\title{
Case Report \\ Eccrine Nevus in the Forearm of a 16-Year-Old Presenting as Unilateral Hyperhidrosis: A Clinicopathological Correlation Paradigm
}

\author{
Alejandro Martin-Gorgojo ${ }^{1, * \mathbb{D}}$, Ignacio Sanchez-Carpintero ${ }^{1}$, Ricardo Ruiz-Rodriguez ${ }^{1}$ \\ and Ana-Belen Enguita-Valls ${ }^{2}$ \\ 1 Dermatology Department, Clínica Dermatológica Internacional, 28001 Madrid, Spain; \\ ignacio@clinicacdi.com (I.S.-C.); ricardo@clinicacdi.com (R.R.-R.) \\ 2 Pathology Department, Clínica Dermatológica Internacional, 28001 Madrid, Spain; abenguita@hotmail.com \\ * Correspondence: alejandromartingorgojo@aedv.es; Tel.: +34-914449797
}

check for updates

Citation: Martin-Gorgojo, A.; Sanchez-Carpintero, I.;

Ruiz-Rodriguez, R.; Enguita-Valls,

A.-B. Eccrine Nevus in the Forearm of

a 16-Year-Old Presenting as

Unilateral Hyperhidrosis: A

Clinicopathological Correlation

Paradigm. Dermatopathology 2021, 8,

446-449. https://doi.org/10.3390/

dermatopathology 8030047

Academic Editor: Gürkan Kaya

Received: 9 August 2021

Accepted: 16 September 2021

Published: 18 September 2021

Publisher's Note: MDPI stays neutral with regard to jurisdictional claims in published maps and institutional affiliations.

Copyright: (c) 2021 by the authors. Licensee MDPI, Basel, Switzerland. This article is an open access article distributed under the terms and conditions of the Creative Commons Attribution (CC BY) license (https:/ / creativecommons.org/licenses/by/ $4.0 /)$.

\begin{abstract}
A case of a purely eccrine nevus in an adolescent patient presenting with focal hyperhidrosis on an area comprising the left forearm and the dorsal aspect of the left hand is described. No clinically evident lesions were identifiable. Dermatopathologic findings were subtle, showing only a slight increase in the number of eccrine glands. Clinicopathological correlation was paramount to achieve the diagnosis.
\end{abstract}

Keywords: eccrine glands; hyperhidrosis; botulinum toxins; type A; neoplasms; adnexal and skin appendage; pathology; clinical; dermatology

\section{Introduction}

Hyperhidrosis is a skin disorder characterized by excessive sweating. It can affect at general, regional, or focal levels. It may have a primary origin, with excessive diaphoresis generally appearing in localized and symmetrical areas, such as axillae, palms, soles, or craniofacial region. Alternatively, it might be secondary to multiple causes, having more frequently a generalized involvement. Some series have quantified primary cases at more than $90 \%$, with secondary cases being infrequent. Regarding the age of onset, most patients initiate excessive sweating between 14 and 25 years of age. However, given the full functionality of the eccrine glands from birth, it can be observed in infants and children [1].

Uncommon causes of secondary focal hyperhidrosis include eccrine nevi. These are considered hamartomas, characterized by hyperplasia and/or hypertrophy of eccrine glands. Eccrine nevi usually affect the forearms (but may have other locations, such as the forehead, the trunk, upper or lower extremities) and present during childhood or adolescence [2]. The anatomical preference for the forearm has been proposed to be related phylogenetically to the antebrachial organ of the lemur catta [3].

The diagnosis of this entity is based on clinical suspicion followed by pathological confirmation. In this manuscript, we present a case highlighting the importance of this clinicopathological correlation.

\section{Case Presentation}

A 16-year-old female patient with no relevant past medical history came to our clinic for evaluation of excessive sweating on an area comprising the left forearm and the dorsal aspect of the left hand. This focal hyperhidrosis started when the patient was four years old, disturbing her during the colder seasons (from November to February, which may be explained by the fact that the patient more frequently wore long-sleeved clothing), and worsened with stressful situations.

Physical examination revealed no apparent cutaneous lesions (Figure 1a). The starchiodine test highlighted the area of hyperhidrosis (Figure 1b). 


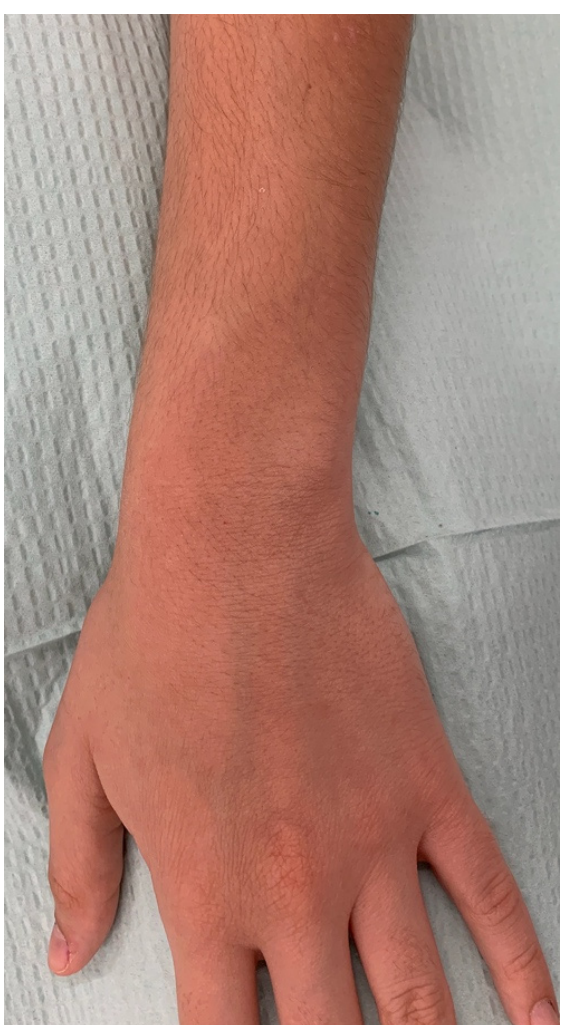

(a)

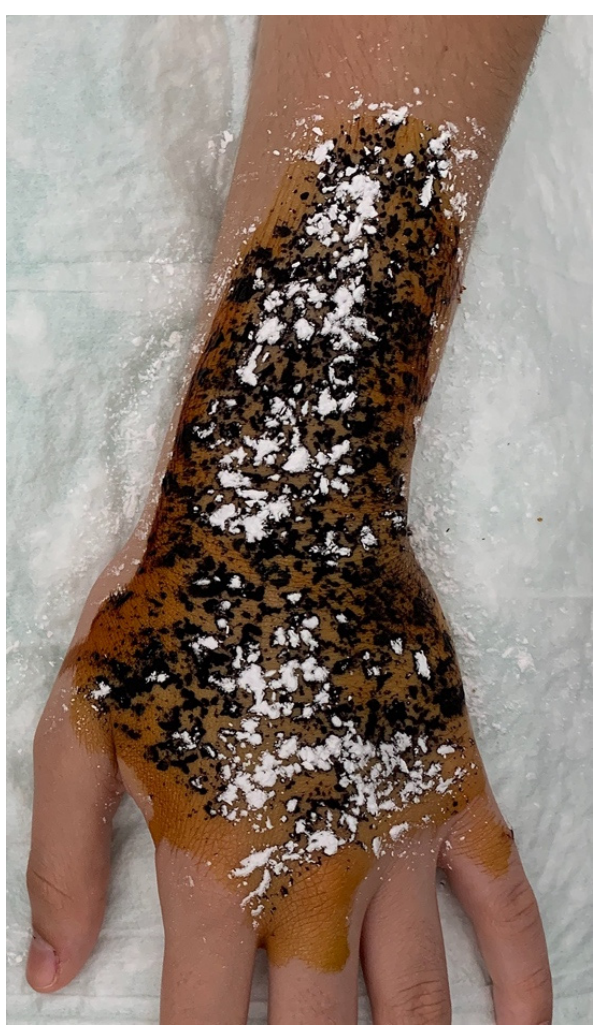

(b)

Figure 1. (a): Dorsal aspect of the patient's left forearm, showing no clinically evident abnormalities. (b): Iodine-starch test (Minor's test) highlighting the hyperhidrosis area.

A punch biopsy was performed. The biopsy showed a slightly increased density of eccrine glands within the dermis, with no other abnormalities (Figure 2).

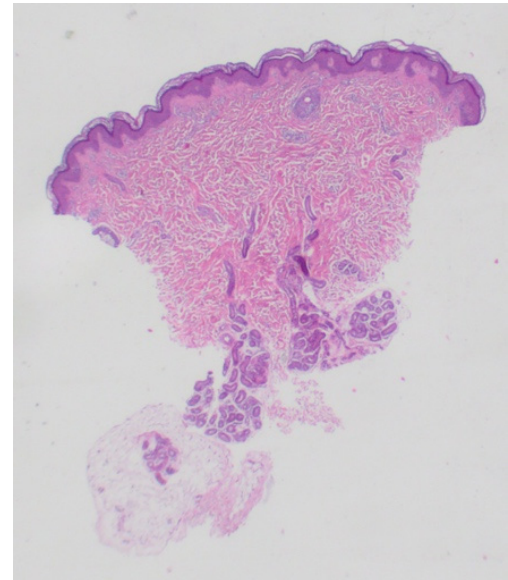

(a)

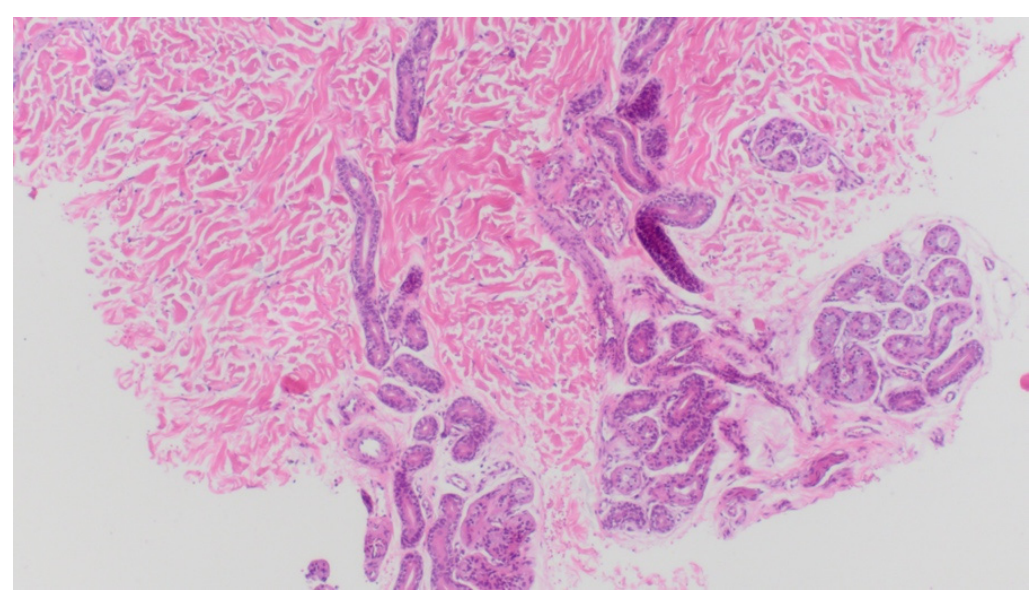

(b)

Figure 2. Punch biopsy sample, hematoxylin-eosin staining. (a): $10 \times$ magnification. (b): 40× magnification.

The patient was treated with multiple intradermal injections of botulinum toxin type A on the affected area, with a satisfactory response, remaining with anhidrosis seven months after follow-up. 


\section{Discussion}

Eccrine nevi are rare lesions included in the group of organoid nevi, with few reported cases in the literature. Clinical features of eccrine nevi are variable, including their age of presentation, number, location, size, signs, and symptoms [4,5].

Most of the cases are only clinically evident when excessive sweating appears, as happened in our case. In some instances, it can be challenging to distinguish eccrine nevi from some forms of idiopathic localized unilateral hyperhidrosis. This hyperhidrosis is focal, on sharply demarcated areas of less than $10 \times 10 \mathrm{~cm}$ in size, and occurs in short episodes frequently worsened by stress [4,6]. However, eccrine nevi may be identified as variably pigmented papules, depressed brown patches, solitary pores draining mucoid material, nodules [7], brownish scaly patches [8], or exceptionally as skin tags [9].

Histopathologically, purely eccrine nevi-such as the depicted case-are considered infrequent [10]. They present with subtle findings, comprising hyperplasia and/or hypertrophy of eccrine sweat glands. Other related organoid nevi may present with additional abnormalities apart from the increase in eccrine glands:

- Angiomatous eccrine nevi (or sudoriparous angiomas) show an augmented number of capillaries [4].

- Eccrine-pilar angiomatous hamartoma comprises hair follicles associated with the eccrine angiomatous complexes [7].

- Mucinous eccrine nevi have abundant mucin deposits around the increased number of ducts of the eccrine glands [11,12].

There are multiple options to treat eccrine nevi. Conservative management is an option if they remain asymptomatic or with mild symptoms. Topical antiperspirants such as aluminum salts plug the eccrine sweat pores, leading to the degeneration of secretory cells. Anticholinergic drugs such as glycopyrrolate work by competitively blocking the activation of eccrine glands. These may yield positive therapeutic results but usually need repeated applications [2] and are insufficient in some cases [13]. Therefore, botulinum toxin type A (which exerts its effect by inhibiting acetylcholine release and thus blocking the activation of eccrine glands) is a reasonable therapeutic option that can lead to satisfactory responses [5].

\section{Conclusions}

A case of a purely eccrine nevus in an adolescent patient presenting with focal hyperhidrosis has been described. Dermatopathologic findings were subtle, and clinicopathological correlation was paramount to achieve the diagnosis.

Author Contributions: A.M.-G.: writing-original draft preparation, review and editing, investigation, project administration, methodology, conceptualization, resources. I.S.-C.: project administration, methodology, conceptualization, resources. R.R.-R.: methodology. A.-B.E.-V.: writing-review, investigation, methodology, conceptualization, resources. All authors have read and agreed to the published version of the manuscript.

Funding: This research received no external funding.

Institutional Review Board Statement: Not applicable.

Informed Consent Statement: The patient granted informed consent to publish the clinical and histological images of her case.

Conflicts of Interest: The authors declare no conflict of interest.

\section{References}

1. Lear, W.; Kessler, E.; Solish, N.; Glaser, D.A. An epidemiological study of hyperhidrosis. Dermatol. Surg. 2007, 33, S69-S75. [CrossRef] [PubMed]

2. Dua, J.; Grabczynska, S. Eccrine nevus affecting the forearm of an 11-year-old girl successfully controlled with topical glycopyrrolate. Pediatric Dermatol. 2014, 31, 611-612. [CrossRef] [PubMed] 
3. Kopera, D.; Soyer, H.P.; Kerl, H. Human eccrine hamartoma of the forearm-antebrachial organ of the ringtailed lemur (Lemur catta). A possible phylogenetic relationship? Am. J. Dermatopathol. 1994, 16, 275-279. [CrossRef] [PubMed]

4. Kawaoka, J.C.; Gray, J.; Schappell, D.; Robinson-Bostom, L. Eccrine nevus. J. Am. Acad. Dermatol. 2004, 51, 301-304. [CrossRef] [PubMed]

5. Lera, M.; España, A.; Idoate, M. Focal hyperhidrosis secondary to eccrine naevus successfully treated with botulinum toxin type A. Clin. Exp. Dermatol. 2015, 40, 640-643. [CrossRef] [PubMed]

6. Parslew, R.; Lewis-Jones, M.S. Localized unilateral hyperhidrosis secondary to an eccrine naevus. Clin. Exp. Dermatol. 1997, 22, 246-247. [CrossRef] [PubMed]

7. Hong, C.E.; Lee, S.H. Multiple eccrine nevus with depressed patches. Yonsei Med. J. 1997, 38, 60-62. [CrossRef] [PubMed]

8. Kang, M.J.; Yu, D.S.; Kim, J.W. A case of eccrine nevus. Ann. Dermatol. 2008, 20, 29-31. [CrossRef] [PubMed]

9. Mahdavy, M.; Smoller, B.R. Eccrine nevus presenting as a perianal skin tag: A case report and review of the literature. Am. J. Dermatopathol. 2002, 24, 361-363. [CrossRef] [PubMed]

10. Ruiz de Erenchun, F.; Vázquez-Doval, F.J.; Contreras Mejuto, F.; Quintanilla, E. Localized unilateral hyperhidrosis: Eccrine nevus. J. Am. Acad. Dermatol. 1992, 27, 115-116. [CrossRef]

11. Tempark, T.; Shwayder, T. Mucinous eccrine naevus: Case report and review of the literature. Clin. Exp. Dermatol. 2013, 38, 1-4. [CrossRef] [PubMed]

12. Rodríguez-Villa Lario, A.; Gómez-Zubiaur, A.; Trasobares-Marugán, L.; Medina-Montalvo, S.; Quesada-Cortés, A.; MedinaExpósito, I. Eccrine mucinous nevus: Clinical and histopathological description in an adult. Dermatol. Online J. $2020,26$. [CrossRef]

13. Ventéjou, S.; Hohl, D.; Bogiatzi, S.; Christen-Zaech, S.; Morren, M.A. Eccrine naevus: Case report with dermoscopic findings. Ann. Dermatol. Venereol. 2021, 148, 66-68. [CrossRef] [PubMed] 